\title{
Majority of Rural Residents Compost Food Waste: Policy and Waste Management Implications for Rural Regions
}

\author{
Meredith T. Niles* \\ Department of Nutrition and Food Sciences \& Food Systems Program, Gund Institute for the Environment, University of \\ Vermont, Burlington, VT, United States
}

A growing number of municipalities and states are implementing household food waste diversion efforts such as curbside compost programs, though these programs present challenges for participation and implementation. While many food waste diversion programs are occurring in densely populated regions, understanding food waste management in rural regions is less studied. This research examines the food waste perceptions and current and future food waste management behaviors of residents in Vermont, one of the most rural U.S. states, through a representative telephone survey of

OPEN ACCESS

Edited by:

Claudia Marques-dos-Santos

Cordovil,

University of Lisbon, Portugal

Reviewed by:

Anne Tremier,

Irstea - Centre de Rennes, France Raquel Barrena, Autonomous University of Barcelona, Spain

${ }^{*}$ Correspondence: Meredith T. Niles mtniles@uvm.edu

Specialty section

This article was submitted to Waste Management in

Agroecosystems, a section of the journal

Frontiers in Sustainable Food Systems

Received: 04 October 2019 Accepted: 19 December 2019

Published: 21 January 2020

Citation:

Niles MT (2020) Majority of Rural Residents Compost Food Waste: Policy and Waste Management Implications for Rural Regions. Front. Sustain. Food Syst. 3:123.

doi: 10.3389/fsufs.2019.00123
Vermont residents $(n=583$ ) in 2018. The findings suggest $55 \%$ of residents support banning food waste from landfills. Furthermore, $72 \%$ of residents compost at least some of their food waste currently and more than $75 \%$ anticipate doing so in the future. Conversely, $34 \%$ of residents anticipate using the garbage or a curbside compost pickup program in the future with urban county residents, renters, and those currently using garbage most interested in curbside programs. The majority of respondents were unwilling to pay anything additional for curbside compost pickup programs. These results suggest food waste management strategies in rural regions may be different than densely populated areas, particularly for programs that may require significant investments and have limited participation given the popularity of home composting. As a result, greater investment in education and infrastructure for backyard composting may be an important component of rural food waste management.

\section{Keywords: curbside compost, garbage disposal, landfill, household food waste, backyard compost}

\section{INTRODUCTION}

Estimates suggest that the amount of food wasted in high-income countries such as the United States may be as high as $40 \%$ of all available food (Gunders et al., 2017), with the majority of this waste coming from the household level and consumer-facing businesses (ReFED, 2016). Simultaneously, knowledge and information about food waste is becoming increasingly prevalent (Neff et al., 2015; Qi and Roe, 2016); however, there is little evidence that this abstract knowledge of food waste (i.e., "food waste is a problem") has led directly to reduced household food waste (Redman and Redman, 2014). Conversely, households indicate that household food waste continues in part because of convenience (Bernstad, 2014; Qi and Roe, 2016), packaging (e.g., size or date labels; Williams et al., 2012), and a lack of confidence in ability to reduce food waste (Qi and Roe, 2016). 
Given these challenges with source reduction of food waste, alternatives to source reduction are increasing, including compost pickup programs, feeding of food waste to livestock, and anaerobic digestion (Thyberg and Tonjes, 2016). Policy efforts for food waste diversion at the household level often focus on curbside pickup programs for composting, which are now mandatory in many urban cities such as San Francisco and Seattle. These programs also may face implementation challenges as well, given that source separation in waste management has been a persistent challenge for the recycling industry (Knickmeyer, 2019). However, these many efforts to curb or repurpose household food waste have largely focused in urban areas (e.g., Silva et al., 2017). Rural states and residents may have different challenges in addressing household food waste, which could require unique policy and behavioral solutions. Despite this, many food waste management studies in rural contexts are from low-income countries (e.g., Nguyen and Watanabe, 2019); there are relatively few studies focused on understanding household food waste perceptions and behaviors in rural areas (Taghipour et al., 2016), especially in high-income countries. This study aims to fill this gap by examining the food waste perspectives and diversion strategies for households in a rural U.S. state.

Many policy efforts to reduce food waste in the U.S. have been focused at the state level (ReFED, 2017). Vermont was the first US state to pass food waste legislation that bans food waste entirely from the waste-stream from all sources including households. The Universal Recycling Law, Act 148, passed unanimously in the Vermont legislature in 2012. Food waste generation in Vermont is an important contribution to landfills, with an estimated $26 \%$ of the total residential waste generated attributed to organics (including yard waste) (Vermont Department of Environmental Conservation, 2018). Including households in the food waste disposal ban was an approach unique from other states (e.g., Massachusetts, Connecticut, California), which have laws requiring large generators of food waste to divert from landfills but not households at the time. Furthermore, Act 148 required garbage haulers to offer food waste pickup for diversion to compost when the legislation was passed, though this requirement has since been changed to only include non-commercial entities and apartment buildings (Vermont Department of Environmental Conservation, 2019).

Vermont is a largely rural state, in fact the second most rural state in the United States (defined by the proportion of its population living in rural areas) (US Census Bureau, 2018). It is also a small state, with an estimated population in 2018 of 626,299 people, making it the second smallest state by population in the United States (US Census Bureau, 2018). Rural regions present unique challenges and opportunities to waste management. Households are further apart, potentially increasing hauling costs. Road infrastructure may be more limited and affect the capacity of large trucks to safely travel. In the case of Vermont, long winters also present unique transportation challenges. Finally, wildlife may present problems for waste disposal, as bears and other animals can be drawn to waste bins, compost, and other recyclables. Conversely, many rural residents have land or gardens that may be utilized for composting or feeding food waste to animals (Nguyen and Watanabe, 2019) and some studies suggest that rural households have less food waste (Mattar et al., 2018) though others have not found this to be true (Thyberg et al., 2015). All of these factors are important to consider in policy and behavioral discussions related to waste management including food waste; yet, rural regions remain understudied in the context of waste management.

Here I aim to fill this gap by examining rural state residents' perceptions of food waste policies, and food waste management behaviors. In particular I ask:

1) Do residents support banning food waste from the landfill?

2) What are the current and future food waste management strategies of residents?

3) How likely and frequently would residents utilize curbside compost pickup programs?

\section{MATERIALS AND METHODS}

Data were collected utilizing the Vermonter poll in 2018, a statewide representative poll, which has been conducted annually since 1996 . The telephone survey was conducted between February 20 and February 26, 2018 through the Center for Rural Studies at The University of Vermont. Institutional Review Board approval for human subjects was obtained prior to the survey through The University of Vermont. The poll utilizes computer aided telephone interviewing drawing from a random sample of Vermont landline and cell phone numbers. Only Vermont residents over the age of 18 were able to participate. The data included here were a sub-set of questions utilized in the survey, which pertained to food waste legislation, behaviors and perceptions as well as demographic and household characteristic questions (Table 1 for an overview of all questions).

Data were aggregated into Excel and analyzed in Stata 15.0 (StataCorp, 2017). Data analysis included the use of chi-square tests, analysis of variance, Kruskal Wallis tests, and logistic regressions as applicable to a given distribution of variables. In addition, a series of ordered logit models were analyzed to examine future food waste strategies and their correlation with current food waste strategies, policy perceptions, food waste attitudes, and demographic and household characteristics.

\section{RESULTS}

\section{Demographics and Response}

A total of 583 Vermont residents over the age of 18 participated in the survey. The study results have a margin of error of $\pm 4.1 \%$ with a $95 \%$ confidence level. People who identified as men were $40.49 \%$ of the respondents, with women encompassing $58.81 \%$ and transgender $<1 \%$. Vermont Department of Health statistics indicate that, among residents over the age of 18 , women make up $51.9 \%$ of the population (Vermont Department of Health, 2017). The three urban classified counties made up $29.88 \%$ of the respondents, with $70.12 \%$ classified as rural counties, as compared to $35 \%$ of the population of Vermont living in urban counties (Vermont Department of Health, 2017). Ninety-one 
TABLE 1 | Variable names, questions and scales utilized for analysis.

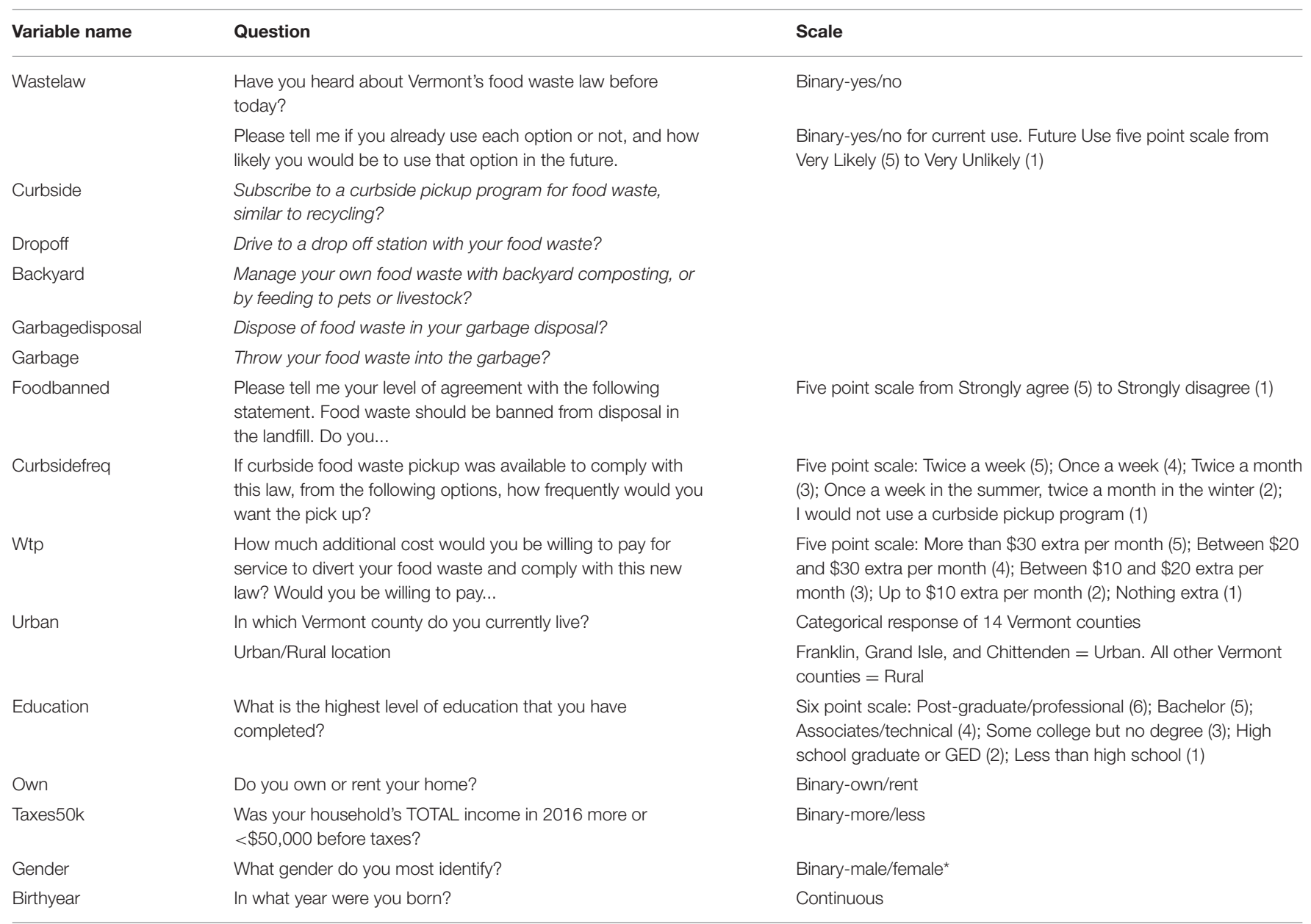

"A small percentage of respondents indicated transgender/other but for statistical purposes, only male and female responses were analyzed.

percent of respondents owned their homes. Education levels varied: from less than a high school diploma (2.28\%), high school diploma or GED (19.33\%), some college (18.98\%), associates or technical degree $(8.44 \%)$, bachelor's degree $(26.89 \%)$, and a postgraduate/professional degree $(24.08 \%)$. Slightly more than twothirds $(68.32 \%)$ had a household income of $\$ 50,000$ before taxes.

\section{Knowledge and Perceptions of Act 148}

The majority (71\%) of respondents had heard about Act 148 , Vermont's food waste law, prior to the survey. Younger Vermonters $(p=0.002)$ and homeowners compared to renters (74.9-43.8\%, $p<0.001)$ were more likely to be aware of the legislation.

Furthermore, the majority of respondents agreed that food waste should be banned from the landfill (56.1\% strong or somewhat agree, Figure 1). Respondents with higher levels of education $(b=0.120, p=0.012)$, women compared to men (mean 3.65-3.35, $p=0.030$ ), those currently using backyard composting (mean 3.70-3.03, $p<0.001$ ), those currently not using garbage disposals (i.e., an appliance installed in a sink to grind food waste and allow it to enter the water system) (mean
3.63 compared to $3.10, p=0.001$ ), and those currently not using garbage as a food waste strategy (mean 3.92 compared to 2.94, $p$ $<0.001$ ) were more likely to agree food waste should be banned from landfills.

\section{Current Food Waste Strategies}

The majority of respondents currently manage their food waste through backyard composting or feeding to pets or livestock $(72.4 \%)$ followed by throwing food waste into the garbage (43.1\%), disposing of food waste in the garbage disposal (i.e., an appliance installed in a sink to grind food waste) (22.0\%), using a drop-off station (18.8\%), and using a curbside pickup program (10.7\%) (Figure 2). Most respondents (45.9\%) used only one strategy to manage food waste, with the most common single use strategy being backyard composting or feeding to pets/livestock (32.5\%) and garbage only (7.9\%). An additional $37.7 \%$ of respondents used two strategies for food waste management, with backyard composting or feeding to pets/livestock and throwing food waste into the garbage together the most common dual strategy (12.6\%). 


\section{Strongly agree}

Somewhat agree

Neither agree nor disagree

Somewhat disagree

Strongly disagree
$32.4 \%$

\section{$23.7 \%$}

\section{$18.0 \%$}

\section{$14.6 \%$}

$11.3 \%$

FIGURE 1 | Level of agreement about banning food waste from landfills.

\section{Manage your own food waste with backyard composting, or by feeding to pets $72.4 \%$ or livestock}

\section{Throw your food waste into the garbage \\ Dispose of food waste in your garbage disposal}

Drive to a drop off station with your food waste Subscribe to a curbside pickup program for
food waste, similar to recycling

\section{$43.1 \%$}

$22.0 \%$

\section{$18.8 \%$}

$10.7 \%$

FIGURE 2 | Strategies used by respondents to currently manage their food waste. Respondents could choose more than one option.

A number of demographic factors were correlated with the use of different food waste strategies. Backyard composting or feeding to pets/livestock was more likely among rural households (76.4 compared to $62.7 \%, p<0.001)$, younger people $(p=0.052)$, and homeowners (73.7 compared to $59.6 \%, p=0.040)$. Using the garbage was more likely among renters ( 57.1 compared to $41.2 \%, p=0.030)$. Garbage disposal use was more likely among urban counties (30.6 compared to $18.2 \%, p=0.001$ ), and with income more than $\$ 50 \mathrm{~K}$ (24.0 compared to $12.3 \%, p=0.002)$. Use of curbside pick-up programs was more likely among larger households $(p=0.052)$. Furthermore, knowledge of Act 148 was also correlated with certain current food waste strategies (Table 2), including less likelihood to utilize the garbage $(39.7 \%$ with knowledge to $51.3 \%$ with no knowledge, $p=0.013$ ) and use curbside pickup programs (9.0 compared to $15.1 \%, p=0.035$ ).

\section{Future Food Waste Strategies}

The majority of respondents (76\%) indicated they would likely manage their food waste in the future through backyard composting or feeding to pets/livestock to comply with Act 148 (Figure 3). Those that were more likely to utilize backyard composting or feeding to pets/livestock were rural counties (mean 4.17-3.79, $p=0.008$ ), larger households ( $p=$ 0.001 ), younger people $(p=0.018)$, and homeowners (mean 4.12 compared to $3.45, p=0.009$ ). Twenty-four percent of
TABLE 2 | Current food waste strategy as a function of knowledge about Vermont's food waste law.

\begin{tabular}{lcc}
\hline Current strategy & $\begin{array}{c}\text { Knowledge of Act } \\
\mathbf{1 4 8}(\boldsymbol{\%})\end{array}$ & $\begin{array}{c}\text { No knowledge of Act } \\
\mathbf{1 4 8}(\boldsymbol{\%})\end{array}$ \\
\hline Backyard composting & 74 & 66.6 \\
Waste in garbage* $^{*}$ & 39.7 & 51.3 \\
Garbage disposal & 20.7 & 25.3 \\
Drop-off station & 18.4 & 18.5 \\
Curbside pickup* & 9.0 & 15.1 \\
\hline
\end{tabular}

Note that respondents could indicate multiple current strategies. "Statistically significant $p<0.05$.

respondents indicated they would be likely to subscribe to a curbside pickup program or continue to throw their food waste in the garbage (technically illegal). Urban counties (mean 2.69 compared to $2.40, p=0.040$ ) and renters (mean 3.09-2.43, $p$ $=0.004$ ) were more likely to use curbside composting. Use of a drop-off station (33\% likely), and the garbage disposal (20\% likely) were less common among respondents. Urban counties (mean 2.21 compared to $1.74, p=0.001$ ) and respondents making more than $\$ 50 \mathrm{~K}$ a year (mean 1.93 compared to 1.60 , $p=0.050$ ), were more likely to use garbage disposals.

Multivariate models to predict the future use of food waste strategies explored multiple factors together including current 


\section{Very Likely $\square$ Somewhat Likely $\square$ Unsure $\square$ Somewhat Unlikely $\square$ Very Unlikely}

\section{Manage your own food waste with backyard composting, or by feeding to pets or livestock}
$66 \%$
Subscribe to a curbside pickup program for food waste, similar to recycling

$10 \%$

$4 \% 6 \%$

\begin{tabular}{l|llll}
$18 \%$ & $16 \%$ & $8 \%$ & $13 \%$ & $45 \%$
\end{tabular}

Throw your food waste into the garbage

\begin{tabular}{l|llll}
$18 \%$ & $16 \%$ & $7 \%$ & $10 \%$ & $50 \%$
\end{tabular}

Drive to a drop off station with your food waste

\begin{tabular}{l|lll|l}
$17 \%$ & $16 \%$ & $7 \%$ & $12 \%$ & $48 \%$
\end{tabular}

Dispose of food waste in your garbage disposal

\begin{tabular}{l|lll|l}
$14 \%$ & $6 \%$ & $4 \%$ & $8 \%$ & $68 \%$
\end{tabular}

FIGURE 3 | Likely future food waste strategies to comply with Act 148.

food waste strategies, knowledge of Act 148, perception of whether food should be banned from a landfill, and a variety of demographic factors (Table 3, Supplementary Tables 1-5). These results suggest that the current food waste strategies are the most predictive of future food waste strategies and that overall respondents are likely to continue to utilize strategies in the future that they use currently. Respondents who currently use curbside pick-up programs $(b=4.153, p<0.001)$, food waste dropoff programs $(b=4.192, p<0.001)$, backyard composting or feeding to pets/livestock $(b=3.933, p<0.001)$, the garbage disposal $(b=0.670, p=0.020)$, and garbage $(b=4.213, p<$ 0.001 ) were more likely to continue to utilize these same strategies in the future. In addition, those currently using garbage as a disposal strategy were also more likely to utilize curbside pickup programs $(b=0.922, p<0.000)$ and dropoff programs $(b=$ $0.813, p=0.001$ ) but less likely to use backyard composting or feeding to pets/livestock $(b=-0.714, p=0.020)$. There were few instances where demographic or household characteristics or food waste attitudes were correlated with future food waste strategies. Younger respondents were more likely to utilize dropoff programs $(b=0.022, p=0.019)$ and backyard compost or feeding to pets/livestock ( $b=0.025, p=0.041)$. Homeowners were less likely to utilize curbside pickup programs $(b=-0.740$, $p=0.054)$ and urban county households were less likely to utilize dropoff programs $(b=-0.526, p=0.027)$ in the future. Finally, those who supported banning food waste from landfills were less likely to utilize garbage in the future as a disposal strategy $(b=$ $-0.227, p=0.016)$.

\section{Curbside Pickup Programs}

Given that Act 148 was proposing a mandatory curbside pickup program across the state, the survey inquired about the potential use and willingness to pay for such a service under Act 148. The most common response for desired frequency of pickup for a curbside food waste program was that respondents would not use such a program (39.6\%). Among those that indicated they would use such a program, $23.0 \%$ wanted pickup once a week, followed by twice a week (14.8\%), once a week in summer and twice a month in winter $(14.8 \%)$, and twice a month $(7.8 \%)$. Household owners wanted the service less frequently (mean 3.59-4.00, $p=$ 0.039 ), while those using a garbage disposal currently wanted the service more frequently (mean 3.84-3.54, $p=0.028$ ). Urban counties $(66.6 \%$ compared to $57.7 \%$ in rural counties, $p=0.046$ as well as those currently using curbside service (90.2 compared to $56.9 \%, p<0.001$ ), garbage disposals (70.5 compared to $57.9 \%$, $p=0.012)$, and garbage (72.7 compared to $51.1 \%, p<0.001)$ were more likely to want to use a curbside pickup program in the future while those using backyard compost were less likely (55.7 compared to $71.2 \%, p=0.004$ ). Older respondents were more likely to want to use a curbside pickup program $(b=$ $0.012, p=0.044$ ), but other demographic factors (i.e., household income, education, knowledge of Act 148, household size) were not significant.

Despite the majority of respondents interested in some frequency of curbside compost pickup, the majority of respondents also indicated they were unwilling to pay anything additional for this service (55.5\%), with $32.4 \%$ willing to pay up to $\$ 10$ extra per month, and far fewer respondents willing to pay more than $\$ 10$ a month (Figure 4).

\section{DISCUSSION}

This study examines the food waste and policy perceptions and behaviors of residents from a rural state, with results having important implications for food waste policy discussions. Among the key findings are that the majority of respondents support 
TABLE 3 | Future food waste management behaviors as predicted by current food waste management behaviors and a number of respondent perceptions and demographics. Five total models are shown here, with the dependent variable name at the top of a column.

\begin{tabular}{|c|c|c|c|c|c|c|c|c|c|c|}
\hline \multirow[b]{2}{*}{ Variable } & \multicolumn{2}{|c|}{ Curbside } & \multicolumn{2}{|c|}{ Dropoff } & \multicolumn{2}{|c|}{ Backyard } & \multicolumn{2}{|c|}{ Garbagedisposal } & \multicolumn{2}{|c|}{ Garbage } \\
\hline & Coefficient & $p=$ & Coefficient & $p=$ & Coefficient & $p=$ & Coefficient & $p=$ & Coefficient & $p=$ \\
\hline \multicolumn{11}{|c|}{ FUTURE FOOD WASTE BEHAVIORS } \\
\hline Curbside & 4.153 & 0.000 & 0.093 & 0.799 & -0.045 & 0.920 & -0.304 & 0.543 & 0.438 & 0.273 \\
\hline Dropoff & 0.200 & 0.434 & 4.192 & 0.000 & -0.688 & 0.035 & -0.765 & 0.046 & -0.002 & 0.994 \\
\hline Backyard & -0.675 & 0.008 & -0.329 & 0.219 & 3.933 & 0.000 & -0.534 & 0.103 & -0.368 & 0.179 \\
\hline Garbagedisposal & -0.078 & 0.762 & 0.208 & 0.440 & -0.131 & 0.684 & 4.821 & 0.000 & 0.670 & 0.020 \\
\hline Garbage & 0.922 & 0.000 & 0.813 & 0.001 & -0.714 & 0.020 & 0.432 & 0.153 & 4.213 & 0.000 \\
\hline Foodbanned & 0.130 & 0.121 & 0.150 & 0.094 & 0.111 & 0.313 & 0.123 & 0.259 & -0.227 & 0.016 \\
\hline Wastelaw & 0.131 & 0.571 & 0.361 & 0.142 & 0.329 & 0.279 & -0.400 & 0.173 & -0.098 & 0.705 \\
\hline Educ & 0.060 & 0.392 & -0.118 & 0.110 & 0.076 & 0.414 & -0.108 & 0.233 & -0.013 & 0.874 \\
\hline Hhsize & -0.035 & 0.610 & -0.092 & 0.408 & 0.113 & 0.384 & 0.122 & 0.132 & 0.086 & 0.231 \\
\hline Birthyear & 0.009 & 0.250 & 0.022 & 0.019 & 0.025 & 0.041 & -0.018 & 0.094 & -0.010 & 0.259 \\
\hline Own & -0.740 & 0.054 & -0.206 & 0.607 & 0.624 & 0.214 & -0.808 & 0.103 & -0.210 & 0.651 \\
\hline Taxes 50k & -0.112 & 0.642 & 0.090 & 0.725 & 0.005 & 0.988 & 0.202 & 0.539 & 0.019 & 0.946 \\
\hline Gender & -0.094 & 0.644 & -0.064 & 0.763 & -0.271 & 0.332 & -0.053 & 0.847 & -0.158 & 0.512 \\
\hline Urban & 0.025 & 0.908 & -0.526 & 0.027 & -0.185 & 0.538 & 0.082 & 0.776 & -0.509 & 0.059 \\
\hline
\end{tabular}

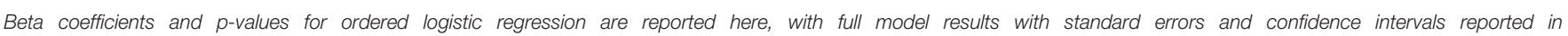
Supplementary Tables 1-5. Variable details, including questions and scales, are provided in Table 1 of the methodology.

\begin{tabular}{l|l} 
Nothing extra & $\mathbf{5 5 . 5 \%}$ \\
\hline Up to $\$ 10$ extra per month & $32.4 \%$ \\
\hline Between $\$ 10-\$ 20$ extra per month & $9.3 \%$ \\
\hline Between $\$ 20-\$ 30$ extra per month & \\
\hline More than $\$ 30$ extra per month &
\end{tabular}

FIGURE 4 | Willingness to pay for curbside compost pickup program.

banning food from the landfill; however, many are already managing their food waste in ways that minimize its introduction into the waste stream. More than $70 \%$ of respondents indicated that they at least manage some of their food waste through backyard composting or feeding to pets/livestock; one-third of respondents indicated that using this strategy was the only way in which they managed food waste. Utilizing backyard composting was most common among rural county residents, younger people and homeowners. These results further suggest that most households will continue to manage their food waste as they currently are (including $34 \%$ who will continue to throw it in the garbage), even with food waste bans set to take place in the state in 2020. Finally, the results find that while $60 \%$ of respondents were interested in some type of curbside compost pickup program, most people are unwilling to pay additionally for this service and demand for the service is most likely in more urban areas and among respondents not utilizing backyard composting or feeding to pets/livestock as a food waste management strategy.

These results are similar to other studies that have found that younger people and homeowners (Park et al., 2002) are more likely to compost. However, the rates of composting found here are significantly higher than other studies. For example, a 2014 survey of Americans found that $28 \%$ of respondents composted their food waste; however more people would be willing to compost if it was more convenient (National Waste Recycling Association, 2014). This difference may explain the high rate of composting found in this study, which was composting specifically in respondents' backyards and more frequently by residents in rural counties. Thus, the rates of composting suggested by this study may be relevant to other rural states and regions, but not reflective of a more suburban or urban population. 
Given this unique outcome, the significant use of backyard composting either as an exclusive food waste management strategy or among one of many, has important implications for food waste management infrastructure and policies in rural states. While there is a growing push for curbside compost pickup programs in more densely populated areas, these results indicate that such efforts may not be effective or efficient in more rural states or regions. Indeed, nearly $40 \%$ of respondents indicated they wouldn't use a curbside compost pickup program at all, and this was more likely among rural county respondents. However, while other studies have found demographic factors such as household size and income to be important predictors of use of curbside recycling or compost programs (Gamba and Oskamp, 1994; Miafodzyeva and Brandt, 2013; Wu et al., 2019), only age was a significant predictor of curbside compost interest in our study, a finding echoed by others (Wu et al., 2019). Furthermore, the majority of those that were interested in a curbside pickup program were unwilling to pay any additional costs. These results mirror other findings in curbside and advanced recycling where consumers are very price sensitive and have low willingness to pay (Blaine et al., 2005; Nixon and Saphores, 2007; Koford et al., 2012). This low willingness to pay may be particularly challenging for implementation in rural areas where economies of scale do not exist because distance between pickup locations is much longer and more costly than in densely populated urban areas (Aadland and Caplan, 2006; Bohm et al., 2010).

Taken together, these results indicate that more tailored approaches to food waste management in rural regions may be warranted. For example, these results indicate that offering curbside compost service in more densely populated areas, with renters, among those currently utilizing garbage services, and not in areas where composting is possible and likely, would generate greater participation, and likely be more cost effective for haulers and municipalities offering the service. Should such efforts be undertaken, convenience of composting, information, and ease of use for participants, which reduces the time of the activity, is shown to increase volume and participation (Refsgaard and Magnussen, 2009; Karim Ghani et al., 2013; Miafodzyeva and Brandt, 2013; Bernstad, 2014; DiGiacomo et al., 2018; Wu et al., 2019), which may be necessary to make the programs cost effective. However, these results also demonstrate that providing additional educational or infrastructure resources to facilitate effective backyard composting may be especially important in rural regions. Existing research suggests that rural composting can be highly efficient and produce good quality compost, which is an effective strategy to remove food waste from the waste stream (Vázquez and Soto, 2017). Knowledge of proper composting methods and systems, which is related to perceived control, is a significant predictor of composting behavior (Taylor and Todd, 1997; Edgerton et al., 2008); thus, efforts to build perceived capacity and knowledge of backyard composting in rural regions may reinforce and maintain these behaviors.

It is also worth noting that nearly one-quarter (24\%) of respondents indicated that they would continue to throw their food waste into the garbage in the future, despite the fact that this would technically be illegal under Act 148 beginning in
2020. Those that were most likely to do so were respondents currently utilizing garbage or garbage disposals in their homes and those that were more likely to disagree that Act 148 should be implemented. Furthermore, respondents currently using the garbage were more likely to be renters, and to have no knowledge of Act 148. As a result, efforts to reduce food waste in landfills after implementation of this law may be particularly challenging with this sub-population of people, who do not support the law itself and already have an engrained behavior. Given that there is currently no enforcement mechanism in place in the law to monitor or penalize non-compliance among households, shifting behavior in this population will be particularly challenging. However, since those currently using garbage were likely to know about the law and be renters, this provides a potential pathway for outreach to shift future behaviors away from using the garbage to dispose of food waste. Additional educational outreach about the law itself, especially to landlords and renting populations, as well as the potential negative consequences of food waste in landfills, or technical and educational assistance for other food waste strategies such as composting may provide some support for shifting these behaviors.

\section{CONCLUSION}

As food waste has continued to grow in recent years, there has been a focus on food waste diversion efforts directed at the household level, where significant portions of food waste are generated in high-income countries. Such efforts including curbside compost pickup programs are growing in popularity in urban areas, but are also being suggested for more rural regions as well. This study examined the food waste perceptions and current and future food waste management behaviors of respondents from the rural state of Vermont. The results suggest that the majority of respondents support banning food from landfills, which may be in part because the majority of respondents were already managing their food waste in ways to minimize its introduction into the waste stream. Backyard composting or feeding food waste to pets or livestock was the most common food waste management behavior currently and in the future. While the majority of respondents indicated their interest in a curbside compost pickup program, most were also unwilling to pay any additional costs associated with such a program.

Since there are unique challenges of implementing a program in a rural region, where economies of scale may not be achievable and costs may be significant, this has important policy implications about the tradeoffs for such efforts. Concentrating compost pickup programs in areas with higher population density may garner the greatest participation. A focus on consumer education and backyard composting infrastructure may provide fruitful outcomes for rural regions where many households are already composting or will do so in the future, and where other food waste management options relevant to densely populated regions may be less viable.

Given the complexity of these challenges and tradeoffs, and the current lack of research on rural food waste 
management strategies, additional research could help fill important gaps in our understanding. This research could focus on assessing food waste strategies and household perceptions in additional rural regions to understand whether these results are more generalizable. As well, interdisciplinary research that could analyze the tradeoffs in food waste strategies across transportation and environmental costs and benefits would be significantly beneficial, and assist rural municipalities in understanding which potential food waste management strategies would be most appropriate for a given scale of community. Finally, as more states and regions are implementing food waste policies, these varying policies offer a natural experiment to understand compliance and policy pathways for achieving reduced food waste and food waste management outcomes, if such policies can measure compliance.

\section{DATA AVAILABILITY STATEMENT}

The datasets generated for this study are available on request to the corresponding author.

\section{ETHICS STATEMENT}

The studies involving human participants were reviewed and approved by University of Vermont. The patients/participants provided their written informed consent to participate in this study.

\section{REFERENCES}

Aadland, D., and Caplan, A. J. (2006). Curbside recycling: waste resource or waste of resources? J. Policy Anal. Manag. 25, 855-874. doi: 10.1002/pam.20211

Bernstad, A. (2014). Household food waste separation behavior and the importance of convenience. Waste Manag. 34, 1317-1323. doi: 10.1016/j.wasman.2014.03.013

Blaine, T. W., Lichtkoppler, F. R., Jones, K. R., and Zondag, R. H. (2005). An assessment of household willingness to pay for curbside recycling: a comparison of payment card and referendum approaches. J. Environ. Manage. 76, 15-22. doi: 10.1016/j.jenvman.2005.01.004

Bohm, R. A., Folz, D. H., Kinnaman, T. C., and Podolsky, M. J. (2010). The costs of municipal waste and recycling programs. Resour. Conserv. Recycl. 54, 864-871. doi: 10.1016/j.resconrec.2010.01.005

DiGiacomo, A., Wu, D. W. L., Lenkic, P., Fraser, B., Zhao, J., and Kingstone, A. (2018). Convenience improves composting and recycling rates in high-density residential buildings. J. Environ. Plan. Manag. 61, 309-331. doi: 10.1080/09640568.2017.1305332

Edgerton, E., McKechnie, J., and Dunleavy, K. (2008). Behavioral determinants of household participation in a home composting scheme. Environ. Behav. 41, 151-169. doi: 10.1177/0013916507311900

Gamba, R. J., and Oskamp, S. (1994). Factors influencing community residents' participation in commingled curbside recycling programs. Environ. Behav. 26, 587-612. doi: 10.1177/0013916594265001

Gunders, D., Bloom, J., Berkenkamp, J., Hoover, D., Spacht, A., and Mourad, M. (2017). Wasted: How America is Losing Up to 40 Percent of Its Food From Farm to Fork to Landfill. Natural Resources Defense Council.

Karim Ghani, W. A., Rusli, I. F., Biak, D. R., and Idris, A. (2013). An application of the theory of planned behaviour to study the influencing factors of participation in source separation of food waste. Waste Manag. 33, 1276-1281. doi: 10.1016/j.wasman.2012.09.019

\section{AUTHOR CONTRIBUTIONS}

MN conceived the research, analyzed the data, and wrote the article.

\section{FUNDING}

This research was funded by Casella Waste Systems, Inc. through a research grant to the University of Vermont. Casella was involved in the formulation of the research questions. They played no role in the data collection, analysis or interpretation of these results.

\section{ACKNOWLEDGMENTS}

The author thanks Deborah Neher and Eric Roy at the University of Vermont Recycling Organics and Resources (ROAR) group for their feedback on the report and the University of Vermont Center for Rural Studies for their data collection efforts.

\section{SUPPLEMENTARY MATERIAL}

The Supplementary Material for this article can be found online at: https://www.frontiersin.org/articles/10.3389/fsufs. 2019.00123/full\#supplementary-material

Knickmeyer, D. (2019). Social factors influencing household waste separation: a literature review on good practices to improve the recycling performance of Urban areas. J. Clean. Prod. 245:118605. doi: 10.1016/j.jclepro.2019.118605

Koford, B., Blomquist, G. C., Hardesty, D. M., and Troske, K. R. (2012). Estimating consumer willingness to supply and willingness to pay for curbside recycling. Land Econ. 88, 745-763. doi: 10.3368/le.88.4.745

Mattar, L., Abiad, M. G., Chalak, A., Diab, M., and Hassan, H. (2018). Attitudes and behaviors shaping household food waste generation: lessons from Lebanon. J. Clean. Prod. 198, 1219-1223. doi: 10.1016/j.jclepro.2018.07.085

Miafodzyeva, S., and Brandt, N. (2013). Recycling behaviour among householders: synthesizing determinants via a meta-analysis. Waste Biomass Valori. 4, 221-235. doi: 10.1007/s12649-012-9144-4

National Waste and Recycling Association (2014). Most Americans Would Compost If It was More Convenient. Washington, DC: PR Newswire.

Neff, R. A., Spiker, M. L., and Truant, P. L. (2015). Wasted food: U.S. Consumers' reported awareness, attitudes, and behaviors. PLOS ONE 10:e0127881. doi: 10.1371/journal.pone.0127881

Nguyen, T. T., and Watanabe, T. (2019). Win-win outcomes in waste separation behavior in the rural area: a case study in Vietnam. J. Clean. Prod. 230, 488-498. doi: 10.1016/j.jclepro.2019.05.120

Nixon, H., and Saphores, J.-D. (2007). Financing electronic waste recycling Californian households' willingness to pay advanced recycling fees. J. Environ. Manage. 84, 547-559. doi: 10.1016/j.jenvman.2006.07.003

Park, W. M., Lamons, K. S., and Roberts, R. K. (2002). factors associated with backyard composting behavior at the household level. Agric. Resour. Econ. Rev. 31, 147-156. doi: 10.1017/S1068280500003968

Qi, D., and Roe, B. E. (2016). Household food waste: multivariate regression and principal components analyses of awareness and attitudes among U.S. Consumers. PLoS ONE 11:e0159250. doi: 10.1371/journal.pone.0159250

Redman, E., and Redman, A. (2014). Transforming sustainable food and waste behaviors by realigning domains of knowledge in our 
education system. J. Clean. Prod. 64, 147-157. doi: 10.1016/j.jclepro.2013. 09.016

ReFED (2016). ReFED Report: A Roadmap to Reduce U.S. Food Waste by $20 \%$. ReFED Organization.

ReFED (2017). U.S. Food Waste Policy Finder [WWW Document]. Available online at: http://www.refed.com/tools/food-waste-policy-finder/ (accessed December 29, 2019).

Refsgaard, K., and Magnussen, K. (2009). Household behaviour and attitudes with respect to recycling food waste - experiences from focus groups. J. Environ. Manage. 90, 760-771. doi: 10.1016/j.jenvman.2008.01.018

Silva, A., Rosano, M., Stocker, L., and Gorissen, L. (2017). From waste to sustainable materials management: three case studies of the transition journey. Waste Manag. 61, 547-557. doi: 10.1016/j.wasman.2016. 11.038

StataCorp (2017). Stata Statistical Software: Release 15. College Station, TX: StataCorp LLC.

Taghipour, H., Amjad, Z., Aslani, H., Armanfar, F., and Dehghanzadeh, R. (2016). Characterizing and quantifying solid waste of rural communities. J. Mater. Cycles Waste Manag. 18, 790-797. doi: 10.1007/s10163-015-0365-z

Taylor, S., and Todd, P. (1997). Understanding the determinants of consumer composting behavior1. J. Appl. Soc. Psychol. 27, 602-628. doi: 10.1111/j.1559-1816.1997.tb00651.x

Thyberg, K. L., and Tonjes, D. J. (2016). Drivers of food waste and their implications for sustainable policy development. Resour. Conserv. Recycl. 106, 110-123. doi: 10.1016/j.resconrec.2015.11.016

Thyberg, K. L., Tonjes, D. J., and Gurevitch, J. (2015). Quantification of food waste disposal in the United States: a meta-analysis. Environ. Sci. Technol. 49, 13946-13953. doi: 10.1021/acs.est.5b03880

US Census Bureau (2018). Population Estimates 2010s. Available online at: https:// www.census.gov/data/tables/time-series/demo/popest/2010s-state-total.html
Vázquez, M. A., and Soto, M. (2017). The efficiency of home composting programmes and compost quality. Waste Manag. 64, 39-50. doi: 10.1016/j.wasman.2017.03.022

Vermont Department of Environmental Conservation (2018). Vermont Waste Categorization Study. Available online at: https://dec.vermont.gov/sites/dec/ files/wmp/SolidWaste/Documents/2018-VT-Waste-Characterization.pdf

Vermont Department of Environmental Conservation (2019). 2019 Summary of Legislative Changes to Vermont SolidWaste Laws. Available online at: https://dec.vermont.gov/sites/dec/files/wmp/SolidWaste/Documents/2019Summary-Changes-Solid-Waste-Law.pdf

Vermont Department of Health (2017). Vermont Population Estimates. Available online at: https://www.healthvermont.gov/sites/default/files/documents/pdf/ STAT_2017_Population_Estimates_Bulletin.pdf

Williams, H., Wikström, F., Otterbring, T., Löfgren, M., and Gustafsson, A. (2012). Reasons for household food waste with special attention to packaging. J. Clean. Prod. 24, 141-148. doi: 10.1016/j.jclepro.2011.11.044

Wu, W.-N., Liu, L.-Y., and Brough, C. (2019). No time for composting: subjective time pressure as a barrier to citizen engagement in curbside composting. Waste Manag. 91, 99-107. doi: 10.1016/j.wasman.2019.04.057

Conflict of Interest: The author declares that the research was conducted in the absence of any commercial or financial relationships that could be construed as a potential conflict of interest.

Copyright (C) 2020 Niles. This is an open-access article distributed under the terms of the Creative Commons Attribution License (CC BY). The use, distribution or reproduction in other forums is permitted, provided the original author(s) and the copyright owner(s) are credited and that the original publication in this journal is cited, in accordance with accepted academic practice. No use, distribution or reproduction is permitted which does not comply with these terms. 